\title{
The Corrosion Behavior of Fe-Ni Alloys in Hydrogen Chloride Gas and Gas Mixtures of Hydrogen Chloride and Oxygen at High Temperatures
}

\author{
By Yoshinao Ihara*, Hideji Ohgame*, \\ Kazutaka Sakiyama* and Koji Hashimoto**
}

\begin{abstract}
Using, iron, $\mathrm{Fe}-12 \% \mathrm{Ni}$ alloy and $\mathrm{Fe}-20 \% \mathrm{Ni}$ alloy, the corrosion behavior in hydrogen chloride gas containing 0-75 vol \% oxygen at temperatures between 523 and $973 \mathrm{~K}$ has been investigated by means of a thermogravimetric technique and by measuring the mass loss and the amount of sublimates. In pure hydrogen chloride gas, the corrosion rate was determined by the formation and sublimation of divalent chlorides of iron and nickel. Up to $673 \mathrm{~K}$, a nearly parabolic scale growth was observed, and addition of nickel to iron suppressed the rates of the corrosion and scale formation. When the temperature exceeded $773 \mathrm{~K}$, sublimation of the corrosion products occurred violently in hydrogen chloride gas, regardless of alloy composition, and hence the corrosion rate was independent of alloy composition. Addition of oxygen to hydrogen chloride gas greatly accelerated corrosion due to the formation and sublimation of a low melting point volatile ferric chloride by oxychlorination.
\end{abstract}

(Received May 10, 1982)

\section{Introduction}

Since metal halides generally possess relatively low melting and boiling points and are often volatile, corrosion of metals in halogen gases is significantly accelerated with increasing temperature. Thus, only a limited number of metals and alloys can be used as structural materials in the environments where metal halides are formed as corrosion products. This fact sometimes restricts the development of new industrial processes.

We have been producing ethylene dichloride, as an intermediate for the production of vinyl chloride monomer, by oxychlorination of ethylene as well as a direct chlorination of ethylene. The structural materials for the oxychlorination process are exposed to a gas mixture of hydrogen chloride, air and ethylene at temperatures between 573 and $723 \mathrm{~K}$. Type 304 stainless steel has presently been used as the structural material in this process. In addition, ethylene dichloride thus produced is converted into

* Central Research Laboratories, Toyo Soda Manufacturing Co., Ltd., 4560 Tonda, Shin Nanyo, Yamaguchi 746, Japan.

** The Research Institute for Iron, Steel and Other Metals, Tohoku University, Sendai 980, Japan. vinyl chloride monomer by thermal cracking up to $823 \mathrm{~K}$ with liberation of hydrogen chloride which is re-used for the oxychlorination process. Type 347 stainless steel has been used as the structural material in the thermal cracking process.

In order to clarify the corrosion behavior of the austenitic stainless steels in these environments, we $\mathrm{e}^{(1)-(3)}$ have studied corrosion of a series of metals and alloys in hydrogen chloride gas and gas mixtures of hydrogen chloride and oxygen at high temperatures. The corrosion rate of iron in pure hydrogen chloride gas was determined by the formation and sublimation of ferrous chloride, and the addition of oxygen to hydrogen chloride gas greatly accelerated corrosion of iron due to the formation and sublimation of a low melting point volatile ferric chloride by oxychlorination reactions ${ }^{(1)}$. On the other hand, the corrosion behavior of nickel in the gas mixtures of hydrogen chloride and oxygen was almost the same as that in hydrogen chloride gas because of exclusive formation of $\mathrm{NiCl}_{2}$ scale, regardless of gas composition ${ }^{(2)}$. Accordingly, the corrosion behavior of iron and nickel in the gas mixtures of hydrogen chloride and oxygen are considerably different, and the corrosion rate of nickel is at least two orders of magnitude lower than that of iron in 
the gas mixtures.

The present work aims to clarify the corrosion behavior of iron-nickel alloys in hydrogen chloride gas and gas mixtures of hydrogen chloride and oxygen at temperatures between 523 and $973 \mathrm{~K}$ to obtain the fundamental knowledge for a better understanding of the corrosion behavior of austenitic stainless steels in these environments.

\section{Experimental}

Pure iron, $\mathrm{Fe}-12 \% \mathrm{Ni}$ alloy and $\mathrm{Fe}-20 \% \mathrm{Ni}$ alloy sheets were prepared by vacuum melting of electrolytic iron and nickel, followed by forging and rolling, and then cut into $0.5 \times 15 \times$ $20 \mathrm{~mm}^{3}$ and $7 \times 10 \times 30 \mathrm{~mm}^{3}$. Their chemical compositions are shown in Table 1. The alloys water-quenched after vacuum annealing at $1173 \mathrm{~K}$ for $18 \mathrm{ks}(5 \mathrm{~h})$ consisted of two phases of $\alpha$ and $\gamma$, whose average grain size was about $30 \mu \mathrm{m}$. The specimens were polished with \#400 emery paper and then degreased with methyl alcohol and ethyl ether.

The specimen mass during corrosion tests at temperatures between 523 and $873 \mathrm{~K}$ in stagnant gases of $10^{5} \mathrm{~Pa}$ was measured periodically by a quartz microbalance. The apparatus ${ }^{(2)}$ consisted of a gas supply system and a vertical reaction tube in which a quartz helix was installed. The maximum mass of $2 \mathrm{~g}$ could be applied to the quartz helix, whose sensitivity was $10.98 \mathrm{mg} / 1 \mathrm{~mm}$ elongation. The displacement of the quartz helix was measured with a cathetometer. The specimen $0.5 \mathrm{~mm}$ in thickness was suspended from the lower end of a quartz rod attached to the quartz helix. After $99.7 \%$ hydrogen chloride gas and $99.9 \%$ oxygen were dried with concentrated sulfuric acid, they were used as reaction gases. Gas mixtures were prepared by mixing them in a tube filled with Rashig rings after the amount of respective gas was controlled by passing through orifice meters. After the reaction tube was heated to a desired temperature under flowing $99.99 \%$ argon with a flow rate of $5.6 \times 10^{-6} \mathrm{~m}^{3} / \mathrm{s}(20 \mathrm{~L} / \mathrm{h})$, argon was replaced with a reaction gas, and then the corrosion test was carried out under a stagnant condition by closing a gas-inlet valve. The oxygen contents of the reaction gases for the thermogravimetric method were 0,20 and $75 \mathrm{vol} \%$.

Corrosion tests were also carried out using the corrosion apparatus ${ }^{(1)}$ consisting of a gas supply system, a horizontal reaction tube and sublimate condensers. This apparatus was suited for the experiment under gas flowing conditions which allowed to collect a large amount of sublimates in the condensers by carrying the corrosion product vapor formed on the thicker specimen of a larger surface area, although the change in specimen mass with time could not be measured by this method. The specimen $7 \mathrm{~mm}$ in thickness was placed on a platinum boat centered in the horizontal reaction tube in the electric furnace, and the corrosion test was carried out at temperatures between 573 and $973 \mathrm{~K}$ for $18 \mathrm{ks}(5 \mathrm{~h})$ under flowing of a reaction gas $1.11 \times 10^{-6} \mathrm{~m}^{3} / \mathrm{s}(4 \mathrm{~L} /$ h). The sublimates, which condensed on the inner walls of the reaction tube, the condensers and the tubes connecting them, were dissolved in an $1 \mathrm{~N} \mathrm{HCl}$ solution at $323 \mathrm{~K}$ and analyzed by means of atomic absorption spectrophotometry. X-ray diffraction was also carried out to identify the sublimates. After the corrosion tests by both methods, the specimens were analyzed by X-ray diffraction and then pickled with $\mathrm{HCl}$ solution containing an inhibitor ( $0.3 \%$ RODINE No. 50, Nippon Paint Co.) for the estimation of the average corrosion rate from the mass loss.

\section{Results}

Figure 1 shows the change in the specimen mass measured by a quartz microbalance dur-

Table 1 Chemical compositions of alloys (mass $\%$ ).

\begin{tabular}{lcccccrr}
\hline \hline & $\mathrm{C}$ & $\mathrm{Si}$ & $\mathrm{Mn}$ & $\mathrm{P}$ & $\mathrm{S}$ & $\mathrm{N}$ & $\mathrm{Ni}$ \\
\hline Pure iron & 0.001 & 0.005 & 0.005 & 0.003 & 0.002 & 0.004 & 0.02 \\
Fe-12\% Ni & 0.001 & 0.006 & 0.006 & 0.002 & 0.003 & 0.004 & 11.91 \\
$\mathrm{Fe}-20 \% \mathrm{Ni}$ & 0.001 & 0.005 & 0.006 & 0.003 & 0.003 & 0.002 & 20.28 \\
\hline \hline
\end{tabular}



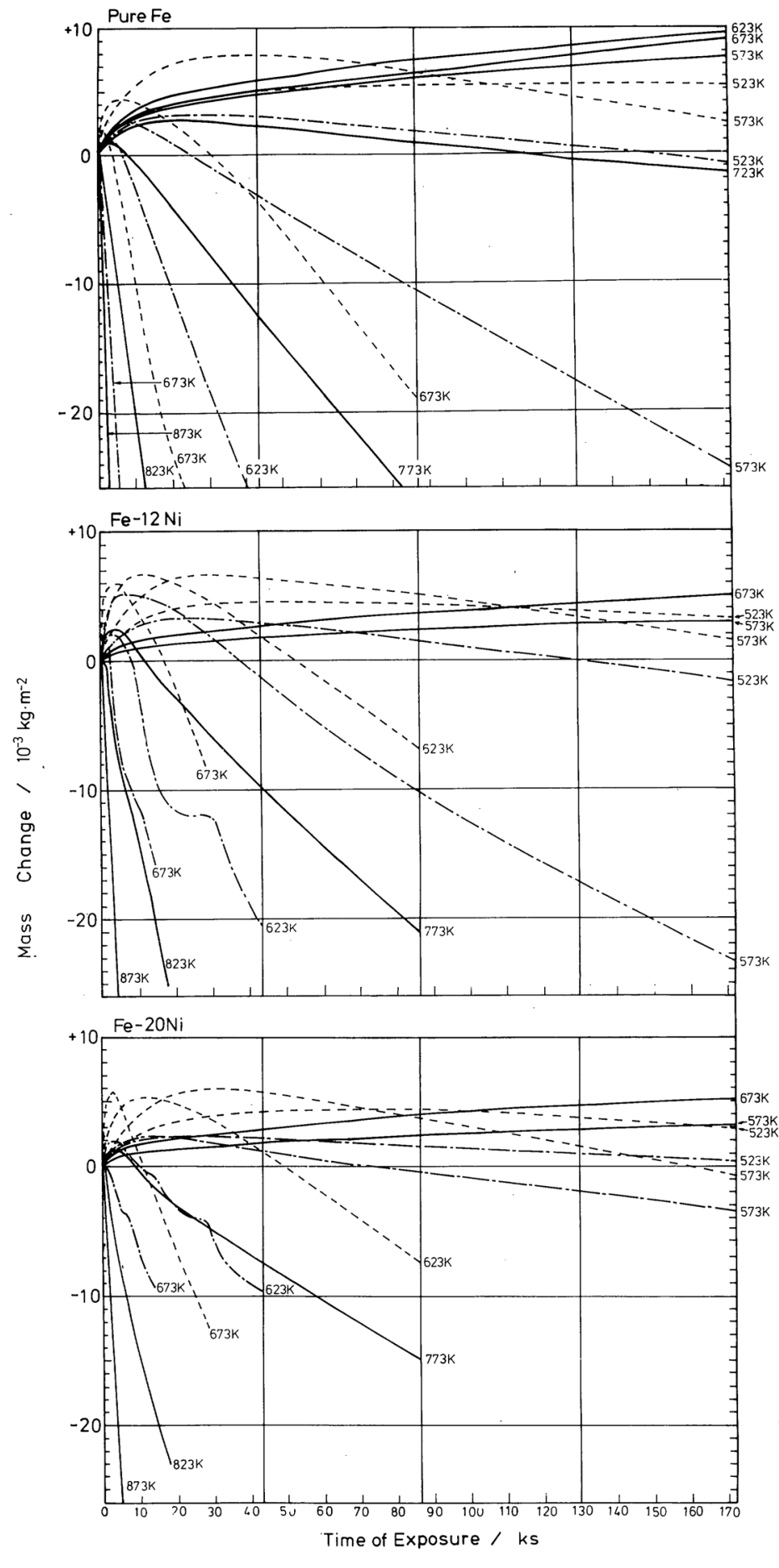

$-100 \% \mathrm{HCl} \quad---80 \% \mathrm{HCl}+20 \% \mathrm{O}_{2} \quad--25 \% \mathrm{HCl}+75 \% \mathrm{O}_{2}$

Fig. 1 Mass changes in pure iron, $\mathrm{Fe}-12 \% \mathrm{Ni}$ alloy and $\mathrm{Fe}-20 \% \mathrm{Ni}$ alloy measured by a quartz microbalance in stagnant hydrogen chloride gas and its mixtures with 20 and $75 \%$ oxygen. 
ing exposure to stagnant reaction gases. At higher temperatures evaporation of corrosion products occurred with a consequent deposition of the corrosion products on the quartz rod suspending the specimen, and hence the mass change shown in Fig. 1 was corrected by substraction of the mass of deposits on the quartz rod from the specimen mass measured; the mass of deposits was estimated from the final mass of deposits after the corrosion test, assuming a constant deposition rate during the corrosion test. As can be seen in Fig. 1, there is no essential difference in corrosion behavior between pure iron and iron-nickel alloys.

In hydrogen chloride gas, up to about $673 \mathrm{~K}$ the specimen mass increases nearly parabolically, suggesting a nearly parabolic scale growth, and the rate of mass gain of ironnickel alloys is slightly lower than that of pure iron. At 723 and $773 \mathrm{~K}$ in hydrogen chloride gas, an initial mass gain is followed by a linear mass decrease accompanying sublimation of bright yellow $\mathrm{FeCl}_{2}{ }^{(1)}$. This suggests that evaporation of scale takes place simultaneously with scale growth, and that the rate of scale evaporation is almost the same as that of the scale growth. It can, therefore, be assumed that the scale thickness becomes constant, at a respective temperature, when the linear mass decrease is observed. At still higher temperatures, the specimen mass linearly decreases as soon as hydrogen chloride gas is introduced into the reaction tube. Accordingly, the reaction of metal with hydrogen chloride gas in the higher temperature range gives rise to gaseous corrosion products, and solid corrosion products are not protective even though they are formed.

In the gas mixtures, a parabolic scale growth is not found and an initial mass gain and a subsequent mass decrease are observed even at low temperatures such as $523 \mathrm{~K}$. Increasing reaction temperature leads to a significant increase in the rate of linear mass decrease and to rapid evaporation of brown-coloured $\mathrm{FeCl}_{3}$ and water. It can, therefore, be said that the addition of oxygen to hydrogen chloride gas leads to the change in corrosion products which have higher vapor pressures and lower melting points.

After the corrosion tests the scale mass was estimated from the mass difference before and after an acid pickling of corroded specimen and is summarized in Table 2. As can be seen in the last column in Table 2, the time of exposure was different with the reaction temperature, since the prolonged corrosion test could not be carried out at higher temperatures because of deposition of evaporated corrosion products in a large amount on the quartz rod suspending the specimen. However, as mentioned above, so long as a linear mass decrease is observed in Fig. 1, the scale seems to attain a constant thickness at a respective temperature, regardless of

Table 2 The scale mass after corrosion tests in stagnant $\mathrm{HCl}$ gas and gas mixtures of $\mathrm{HCl}$ and $\mathrm{O}_{2}\left(10^{-3} \mathrm{~kg} / \mathrm{m}^{2}\right)$.

\begin{tabular}{|c|c|c|c|c|c|}
\hline Gas & $\begin{array}{l}\text { Specimen } \\
\text { Temp. K }\end{array}$ & Pure Fe & $\mathrm{Fe}-12 \% \mathrm{Ni}$ & $\mathrm{Fe}-20 \% \mathrm{Ni}$ & $\begin{array}{l}\text { Time of } \\
\text { exposure } \\
\text { (ks) }\end{array}$ \\
\hline \multirow{5}{*}{$100 \% \mathrm{HCl}$} & 573 & 14.2 & 5.5 & 5.7 & 172.8 \\
\hline & 673 & 21.7 & 10.1 & 10.9 & 172.8 \\
\hline & 773 & 9.8 & 18.7 & 27.3 & 86.4 \\
\hline & 873 & 8.4 & 20.2 & 28.8 & 18.0 \\
\hline & 973 & 7.2 & 22.1 & 29.8 & 10.8 \\
\hline \multirow{4}{*}{$80 \% \mathrm{HCl}+20 \% \mathrm{O}_{2}$} & 523 & 10.9 & 8.7 & 6.6 & 172.8 \\
\hline & 573 & 15.7 & 16.7 & 12.4 & 172.8 \\
\hline & 623 & 11.9 & 20.4 & 23.6 & 86.4 \\
\hline & 673 & 8.6 & 32.1 & 27.1 & 28.8 \\
\hline \multirow{4}{*}{$25 \% \mathrm{HCl}+75 \% \mathrm{O}_{2}$} & 523 & 6.4 & 6.5 & 3.4 & 172.8 \\
\hline & 573 & 9.3 & 21.0 & 13.1 & 172.8 \\
\hline & 623 & 8.5 & 30.7 & 20.0 & 43.2 \\
\hline & 673 & 8.4 & 22.9 & 26.6 & 14.4 \\
\hline
\end{tabular}


the time of exposure, due to the simultaneous growth and evaporation of scale at the same rate. In other words, corrosion seems to continue at a constant rate of metallic-loss, and hence the corrosion rate may be estimated by dividing final metallic loss by time of exposure; these are shown in Fig. 2 in which the average corrosion rate of nickel $^{(2)}$ is also shown for comparison. Since a nearly parabolic scale growth was observed in hydrogen chloride gas at $673 \mathrm{~K}$ or lower temperatures as shown in Fig. 1, the average corrosion rate estimated from further prolonged corrosion tests in pure hydrogen chloride gas in these temperature range would be lower than those shown in Fig. 2. Only in this temperature range the corrosion rate of iron-nickel alloys in hydrogen chloride gas is different from that of iron, showing lower values. Under these conditions, the mass of scale on the iron-nickel alloys is smaller than that on pure iron as shown in Table 2. These results suggest that the addition

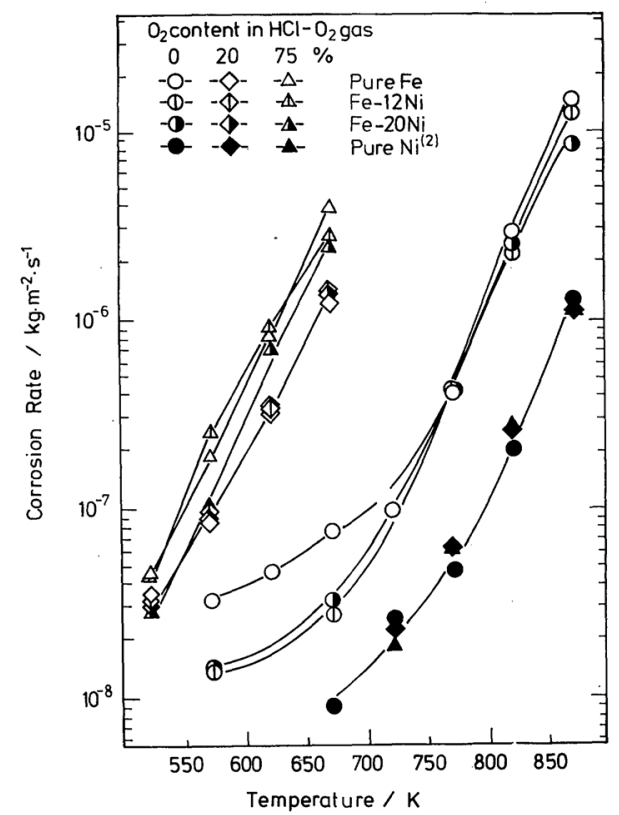

Fig. 2 Average corrosion rates of iron and $\mathrm{Fe}-\mathrm{Ni}$ alloys in hydrogen chloride gas and its mixtures with 20 and $75 \%$ oxygen. The average corrosion rates were estimated from the mass losses after corrosion products were removed from the specimens corroded in the stagnant reaction gases for times shown in Table 2. The corrosion rate of nickel $^{(2)}$ are also shown for comparison. of nickel to iron decreases the growth rate of scale in this temperature range in hydrogen chloride gas, and hence decreases the corrosion rate. At still higher temperatures in hydrogen chloride gas, the corrosion rate increases logarithmically with increasing temperature, regardless of alloy composition, despite the fact that the scale mass significantly increases with increasing nickel content of alloys (Table 2). For instance, at $773 \mathrm{~K}$, the masses of metallic ions in the scale formed on iron, $\mathrm{Fe}-12 \mathrm{Ni}$ alloy and $\mathrm{Fe}-20 \mathrm{Ni}$ alloy in hydrogen chloride gas were about 14, 26 and $38 \%$ of the total metallic losses, respectively, when we assumed that the scale consists of $\mathrm{FeCl}_{2}$ on iron and a mixture of $\mathrm{FeCl}_{2}$ and $\mathrm{NiCl}_{2}$ on $\mathrm{Fe}-\mathrm{Ni}$ alloys in hydrogen chloride gas. Accordingly, the addition of nickel to iron seems to decrease the evaporation rate of the scale, although it does not improve appreciably the protective quality of the scale at $773 \mathrm{~K}$ or higher temperatures in hydrogen chloride gas. The corrosion rate in this temperature range in hydrogen chloride gas increases logarithmically with increasing temperature in parallel with that of nickel.

The addition of oxygen to hydrogen chloride gas significantly increases the corrosion rate of iron and iron-nickel alloys (Fig. 2). At $523 \mathrm{~K}$ where the scale evaporates but is somewhat protective, the addition of nickel to iron leads to a decrease in the scale growth rate (Table 2) with a consequent slight decrease in the corrosion rate (Fig. 2). When the reaction temperature is raised, the addition of nickel increases the scale mass in the gas mixtures, but is not effective in decreasing the corrosion rate, suggesting the poor protectivity of the scale.

At temperatures higher than $673 \mathrm{~K}$ the corrosion rate in the gas mixtures was considerably high due to rapid evaporation of corrosion products, which resulted in the rapid deposition of corrosion products in a large amount on the quartz rod suspending the specimen. It became, therefore, difflcult to measure the mass change of thin specimen by a microbalance at higher temperatures. In order to investigate the corrosion behavior in a wide temperature range, the corrosion test was carried out for $18 \mathrm{ks}(5 \mathrm{~h})$ under gas flowing conditions using a horizontal reaction tube in which a thicker specimen was 
placed. After the corrosion test in the horizontal reaction tube, the specimen was analyzed by Xray diffraction and then pickled with hydrochloric acid for the measurement of final metallic loss. The average corrosion rate was estimated from the metallic loss and is shown in Fig. 3 as a function of reaction temperature. The difference in the corrosion rates shown in Figs. 2 and 3 may not be based on the difference in the experimental conditions such as in stagnant and flowing gases, but seems to be due to the difference in the times of corrosion tests. For instance, in hydrogen chloride gas the average corrosion rates estimated from the tests for $172.8 \mathrm{ks}(48 \mathrm{~h})$ at $573 \mathrm{~K}$ or $673 \mathrm{~K}$ (Fig. 2) were about one order of magnitude lower than those estimated from the test for $18 \mathrm{ks}(5 \mathrm{~h})$ (Fig. 3), but the rate estimated from the test for $10.8 \mathrm{ks}$ $(3 \mathrm{~h})$ at $873 \mathrm{~K}$ (Fig. 2) was higher than that of $18 \mathrm{ks}(5 \mathrm{~h})$ (Fig. 3). In gas mixtures at $573 \mathrm{~K}$, the evaporation of protective scale was not remarkable, and hence the average corrosion rates of iron-nickel alloys estimated from the corrosion tests for $182.4 \mathrm{ks}$ (Fig. 2) were about $1 / 3$ of those of $18 \mathrm{ks}$ (Fig. 3). Since the scale

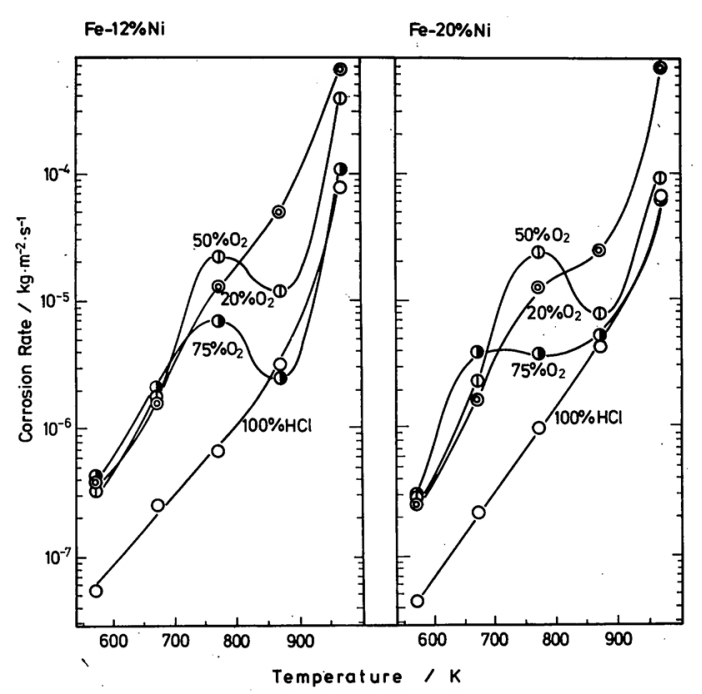

Fig. 3 Changes in average corrosion rates of $\mathrm{Fe}-$ $12 \% \mathrm{Ni}$ and $\mathrm{Fe}-20 \% \mathrm{Ni}$ alloys in hydrogen chloride gas and its mixtures with oxygen as a function of temperature. The average corrosion rates were estimated from the mass losses after corrosion products were removed from specimens which were exposed to the flowing reaction gases for $18 \mathrm{ks}$ (5 h). evaporation was rapid at $673 \mathrm{~K}$ in the gas mixtures, the difference in the corrosion rates estimated from the different times of corrosion tests was not significant, suggesting that the corrosion rate under these conditions was primarily determined by the evaporation of corrosion products.

The following are observed in Fig. 3: The corrosion rates of two alloys in the gas mixture containing $20 \%$ oxygen are about one order of magnitude higher than that in pure hydrogen chloride gas in the temperature range measured. In the gas mixture with $50 \%$ oxygen the corrosion rates of two alloys increase with increasing temperature up to $773 \mathrm{~K}$ in parallel with those in pure hydrogen chloride gas and show maxima at $773 \mathrm{~K}$. The corrosion rates of both alloys in the gas mixture with $50 \%$ oxygen decrease with increasing temperature from 773 to $873 \mathrm{~K}$, but further increase in the reaction temperature results in a logarithmic rise in the corrosion rate. In the gas mixture with $75 \%$ oxygen the corrosion rate of $\mathrm{Fe}-12 \mathrm{Ni}$ alloy shows a maximum at $773 \mathrm{~K}$ and becomes almost the same as those in pure hydrogen chloride at 873 and $973 \mathrm{~K}$. The corrosion rate of $\mathrm{Fe}-20 \mathrm{Ni}$ alloy, however, in the gas mixture with $75 \%$ oxygen increases logarithmically with increasing temperature from 573 to $673 \mathrm{~K}$ and 873 to $973 \mathrm{~K}$, and is almost unchanged within the intermediate temperature range from 673 to $873 \mathrm{~K}$.

Figure 4 summarizes the change in the mass of iron found in sublimates with the gas composition and temperature, and Table 3 shows the compositions of scales and sublimates. In pure hydrogen chloride gas an appreciable sublimate was not formed up to $673 \mathrm{~K}$, while at $773 \mathrm{~K}$ a small amount of bright yellow-colored dry sublimates condensed on the inner wall of the reaction tube, the condensers and the tubes connecting them. At 873 and $973 \mathrm{~K}$ in pure hydrogen chloride gas the ratio of iron found in sublimates to total mass loss was significantly high and a large amount of bright yellow and scaly pale yellow sublimates condensed in the rear part of the reaction tube. It has been known that the corrosion products on iron and nickel in hydrogen chloride gas are $\mathrm{FeCl}_{2}{ }^{(1)}$ and $\mathrm{NiCl}_{2}^{(2)}$, respectively. The scaly pale yel- 


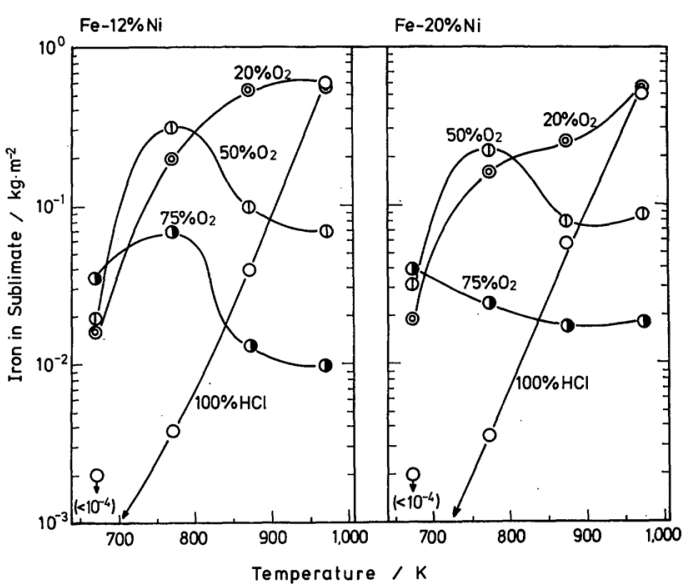

Fig. 4 Changes in the mass of iron in sublimates condensed on the inner walls of the reaction tube, condensers and tubes connecting them during exposure to the flowing reaction gases for $18 \mathrm{ks}$. The mass is expressed in kilogram per surface area of specimen. The numbers in brackets denote the mass of iron found in the sublimate at $673 \mathrm{~K}$ in pure hydrogen chloride gas.

low sublimate was not deliquescent in the atmosphere and was identified as $\mathrm{NiCl}_{2}$ by $\mathrm{X}$-ray diffraction. On the other hand, as soon as air was introduced into the reaction tube the bright yellow sublimate became deliquescent and hence was assumed as $\mathrm{FeCl}_{2}{ }^{(1)}$. The scale on the specimen was also deliquescent in the atmosphere. Since the growth rate of scale on the iron-nickel alloys at lower temperatures was slower than that on pure iron and since both $\mathrm{FeCl}_{2}$ and $\mathrm{NiCl}_{2}$ were assumed to exist in the sublimates, the scale formed on iron-nickel alloys in pure hydrogen chloride gas seemed to be $\mathrm{Fe}(\mathrm{Ni}) \mathrm{Cl}_{2}$, and fractional sublimation might lead to separation of sublimates into $\mathrm{FeCl}_{2}$ and $\mathrm{NiCl}_{2}$. At $973 \mathrm{~K}$ corrosion was accelerated due to melting of $\mathrm{FeCl}_{2}$ whose melting point was $949 \mathrm{~K}^{(4)}$

In the gas mixtures at $673 \mathrm{~K}$ brown-colored $\mathrm{FeCl}_{3}{ }^{(1)}$ and water drops condensed mainly on the inner wall of the rear part of the horizontal reaction tube and then became a browncolored solution at the end of the corrosion test. Since $\mathrm{FeCl}_{3}$ was formed by oxychlorination of iron ${ }^{(1)}$, an increase in the oxygen content of the gas mixtures was liable to accelerate the formation and evaporation of $\mathrm{FeCl}_{3}$ at $673 \mathrm{~K}$. At $773 \mathrm{~K}$ or higher temperatures the scaly pale yellow-colored $\mathrm{NiCl}_{2}$ also sublimed along with the formation of the brown-colored $\mathrm{FeCl}_{3}$ solution in the rear part of the horizontal reaction tube.

After the corrosion test at $673 \mathrm{~K}$ in the gas mixtures X-ray diffraction patterns of the specimens were composed of intense lines of $\mathrm{NiCl}_{2}$ (or $\mathrm{FeCl}_{2}$ ) and weak lines of $\alpha-\mathrm{Fe}_{2} \mathrm{O}_{3}$, along with those of $b c c$ and $f c c$ metallic phases. The scale consisted of an outer pale yellow-colored layer and a very thin inner greyish layer. The scale was not uniform but contained many cracks which reached the scale-metal interface. Although it was difficult to distinguish between $\mathrm{NiCl}_{2}$ and $\mathrm{FeCl}_{2}$ by X-ray diffraction, the outer layer was assumed as $\mathrm{NiCl}_{2}$ and the inner layer as $\alpha-\mathrm{Fe}_{2} \mathrm{O}_{3}$, because contrary to the deliquescent $\mathrm{Fe}(\mathrm{Ni}) \mathrm{Cl}_{2}$ scale the outer layer was not deli-

Table 3 Scales and sublimates for iron-nickel alloys corroded in hydrogen chloride gas and gas mixtures of hydrogen chloride and oxygen.

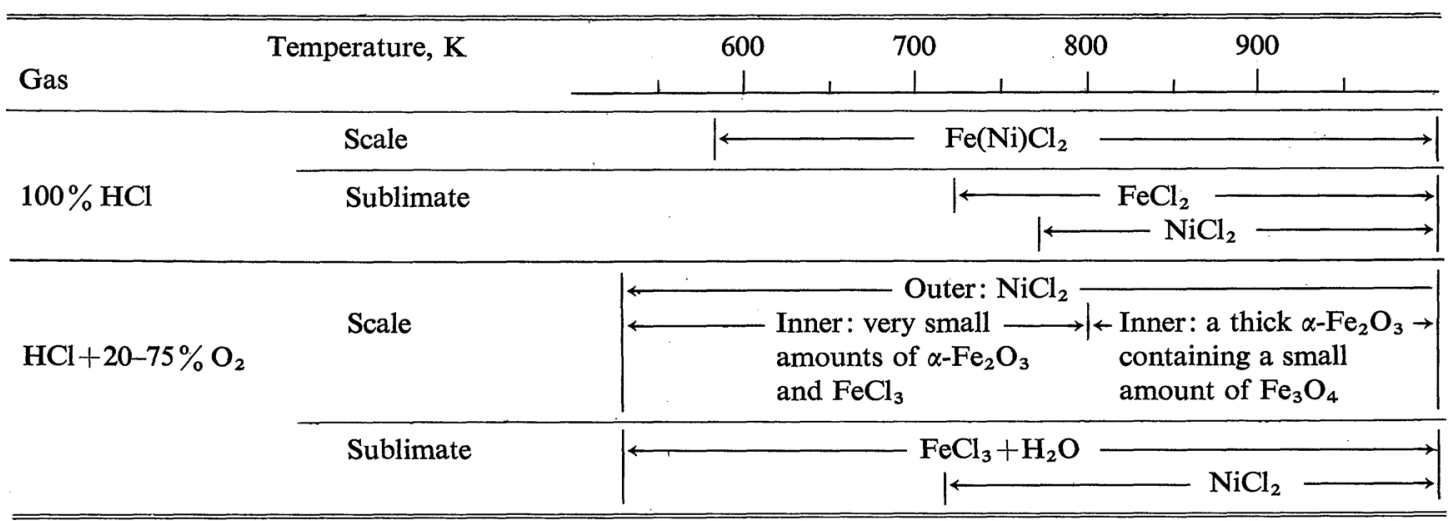


quescent in the atmosphere. In addition, a small amount of brown-colored, deliquescent corrosion product was found in the scale-metal interface and was assumed as $\mathrm{FeCl}_{3}$. The outer $\mathrm{NiCl}_{2}$ layer formed on the $\mathrm{Fe}-20 \mathrm{Ni}$ alloy in the gas mixtures at $773 \mathrm{~K}$ or higher temperatures was significantly thicker than that of the $\mathrm{NiCl}_{2}$ layer on the $\mathrm{Fe}-12 \mathrm{Ni}$ alloy. As can be seen in Fig. 4 , in the gas mixture with $20 \%$ oxygen the mass of iron found in the sublimates increases with increasing temperature. On the other hand, in the gas mixture with $50 \%$ oxygen both the corrosion rate and mass of iron in the sublimates show the maxima at $773 \mathrm{~K}$, and a further rise in reaction temperature decreases the amount of iron in the sublimates due to thickening of the inner $\alpha-\mathrm{Fe}_{2} \mathrm{O}_{3}$ layer of the scale. The inner oxide layer was also defective with many cracks, suggesting that oxychlorination occurred directly at the scale-metal interface along with conversion of oxide to $\mathrm{FeCl}_{3}{ }^{(1)}$. When the oxygen content of the reaction gas was higher at 873 or $973 \mathrm{~K}$, the inner $\alpha-\mathrm{Fe}_{2} \mathrm{O}_{3}$ layer became thicker and weak diffraction lines of $\mathrm{Fe}_{3} \mathrm{O}_{4}$ were also observed from the specimens corroded in these temperatures. No nickel oxide was identified in the scale formed on the iron-nickel alloys in the gas mixtures at all temperatures examined, although $\mathrm{NiFe}_{2} \mathrm{O}_{4}$ might exist since it was difficult to distinguish between $\mathrm{Fe}_{3} \mathrm{O}_{4}$ and $\mathrm{NiFe}_{2} \mathrm{O}_{4}$ from weak diffraction lines.

\section{Discussion}

\section{In pure hydrogen chloride gas}

A nearly parabolic scale growth was found up to $673 \mathrm{~K}$, and at still higher temperatures an initial scale growth was followed by linear mass decrease due to evaporation of corrosion products. The corrosion products on ironnickel alloys seemed to consist of $\mathrm{Fe}(\mathrm{Ni}) \mathrm{Cl}_{2}$. $\mathrm{NiCl}_{2}$ is thermally more stable than $\mathrm{FeCl}_{2}$; their melting points are about $1303 \mathrm{~K}^{(4)}$ and $949 \mathrm{~K}^{(4)}$ and their vapor pressure is $0.1 \mathrm{~Pa}$ $\left(10^{-6} \mathrm{~atm}\right)$ at $773^{(4)}$ and $673 \mathrm{~K}^{(4)}$, respectively. Both $\mathrm{FeCl}_{2}$ and $\mathrm{NiCl}_{2}$ have a hexagonal structure of a cadmium chloride type and their lattice constants are not largely different as
$0.621 \mathrm{~nm}^{(6)}$ and $0.613 \mathrm{~nm}^{(7)}$, respectively. Accordingly, $\mathrm{Ni}^{2+}$ ion seems to replace $\mathrm{Fe}^{2+}$ ion in $\mathrm{FeCl}_{2}$ crystal without large lattice distortion, and the incorporation of $\mathrm{Ni}^{2+}$ in $\mathrm{FeCl}_{2}$ may improve the protective quality of the scale at relatively low temperatures where $\mathrm{NiCl}_{2}$ is not thermally unstable.

Since sublimation of scale was not observed at temperatures between 573 and $673 \mathrm{~K}$, the gross parabolic scaling rate constant during chlorination of iron and iron-nickel alloys, $K_{\mathrm{p}}$, can be estimated as the product of the gradient for the plot of the square of mass change versus time and the square of the ratio of the molecular weight of the divalent chloride scale to that of chlorine. It was assumed for the calculation that the ratio of iron to nickel in the $\mathrm{Fe}(\mathrm{Ni}) \mathrm{Cl}_{2}$ scale is the same as that in the bulk alloy. At still higher temperatures, if the fixed composition of the scale is maintained during corrosion, the mass change of scale, $\mathrm{d} X / \mathrm{d} t$, can be expressed as ${ }^{(8)}$ :

$$
\mathrm{d} X / \mathrm{d} t=\left(K_{\mathrm{p}} / 2 X\right)-K_{\mathrm{s}},
$$

where $X$ is the scale mass and $K_{\mathrm{s}}$ is the linear rate constant for scale evaporation. When the specimen mass decreases linearly, it can be assumed that the rate of parabolic scale growth is equal to the rate of scale evaporation from the scale surface, and hence that the scale mass becomes constant $(\mathrm{d} X / \mathrm{d} t=0)$. Accordingly,

$$
K_{\mathrm{p}} / 2 X_{\mathrm{ss}}=K_{\mathrm{s}} \text {. }
$$

$K_{\mathrm{s}}$ can be estimated by multiplying the rate of linear mass decrease by the ratio of the molecular weight of the scale to the atomic weight of the substrate metal. Since $X_{\mathrm{ss}}$ is the scale mass under steady state conditions where the formation rate of scale seems to be equal to the evaporation rate of scale, one can assume $X_{\mathrm{ss}}$ as the scale mass shown in Table 2 and hence can estimate $K_{\mathrm{p}}$. The method was not applied to the iron-nickel alloys as described later. $K_{\mathrm{p}}$ and $K_{\mathrm{s}}$ thus estimated are shown as a function of the reciprocal of absolute temperature in Figs. 5 and 6 , respectively. The data for pure nickel ${ }^{(2)}$ are also shown in these figures for comparison. As can be seen in Fig. 5, the activation energy for $\mathrm{Fe}(\mathrm{Ni}) \mathrm{Cl}_{2}$ scale growth on iron-nickel alloys is different from that for $\mathrm{NiCl}_{2}$ scale 


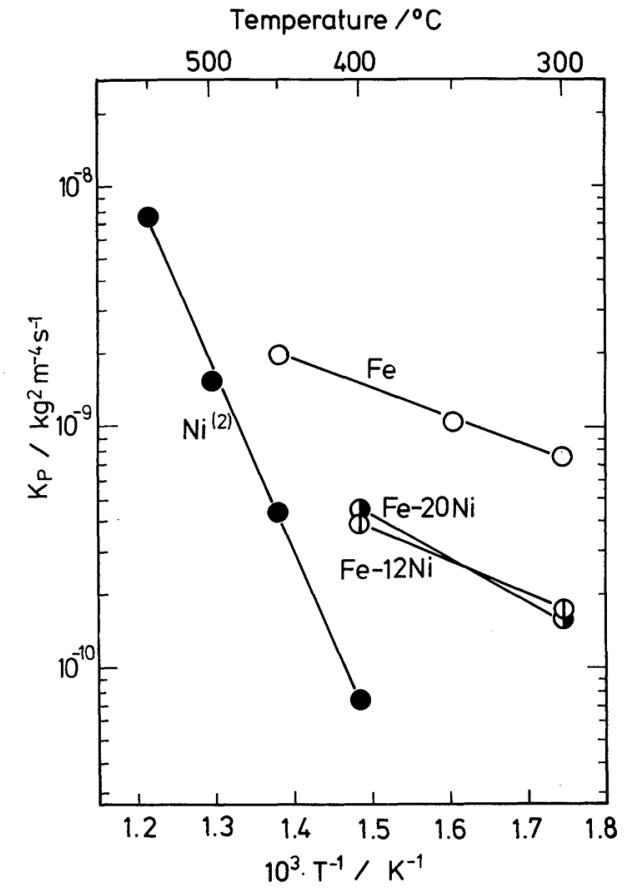

Fig. 5 Parabolic rate constants for scale growth from the measurements of mass changes in specimens of pure iron and $\mathrm{Fe}-\mathrm{Ni}$ alloys exposed to stagnant hydrogen chloride gas as shown in Fig. 1. Those for nickel in hydrogen chloride $\operatorname{gas}^{(2)}$ are also shown for comparison.

growth on nickel, but is almost the same as that for $\mathrm{FeCl}_{2}$ scale growth on iron. Nevertheless, the growth rate of $\mathrm{Fe}(\mathrm{Ni}) \mathrm{Cl}_{2}$ scale on iron-nickel alloys is significantly lower than the growth rate of $\mathrm{FeCl}_{2}$ scale on iron. The slow growth of $\mathrm{Fe}(\mathrm{Ni}) \mathrm{Cl}_{2}$ scale seems responsible for the slow corrosion rate of iron-nickel alloys up to $673 \mathrm{~K}$ in pure hydrogen chloride gas, where scale evaporation was not significant.

The evaporation rate of $\mathrm{NiCl}_{2}$ is slower than that of $\mathrm{FeCl}_{2}$, as shown in Fig. 6. Accordingly, the scale mass at temperatures between 773 and $873 \mathrm{~K}$ in pure hydrogen chloride gas increases by the addition of nickel to iron, as can be seen in Table 2. Nevertheless, the corrosion rate was almost independent of alloy composition under those conditions, and hence the addition of nickel to iron cannot improve the protective quality of the scale when $\mathrm{FeCl}_{2}$ evaporation from the scale occurs, and these results suggest that the above-mentioned model expressed by

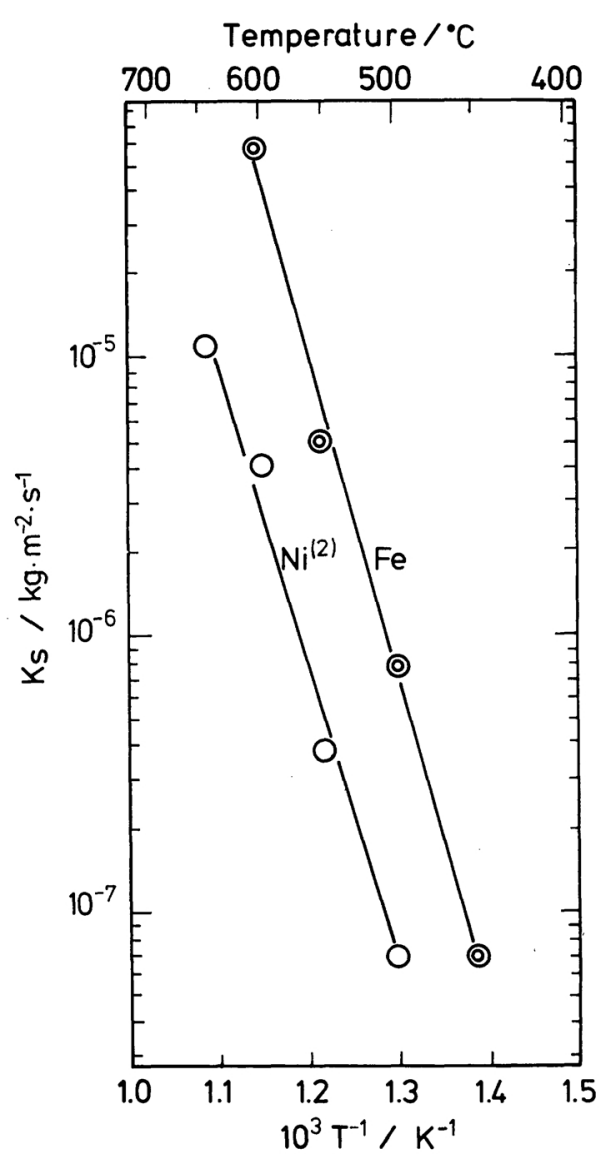

Fig. 6 Linear rate constants for $\mathrm{FeCl}_{2}$ sublimation estimated from the measurements of mass changes in iron specimens exposed to stagnant hydrogen chloride gas. Those for the $\mathrm{Ni}-\mathrm{HCl}$ system $^{(2)}$ are also shown for comparison.

eq. (1), that is, the simultaneous parabolic scale growth and its evaporation from the scale surface cannot be applied to the iron-nickel alloys in hydrogen chloride gas at $773 \mathrm{~K}$ or higher temperatures due to the formation of defective scale, whose composition gradually changes as a result of preferential sublimation of $\mathrm{FeCl}_{2}$.

\section{In the gas mixtures of hydrogen chloride and oxygen}

It was found that the addition of nickel to iron was not effective in improving the corrosion resistance in the gas mixtures. The present authors $^{(1)}$ reported that the addition of oxygen to hot hydrogen chloride gas significantly accelerates corrosion of iron due to the forma- 
tion of a low melting point volatile $\mathrm{FeCl}_{3}$ by oxychlorination, while only $\mathrm{FeCl}_{2}$ can be formed in pure hydrogen chloride gas. $\mathrm{FeCl}_{3}$ possesses a low melting point $(576 \mathrm{~K})$ and a high vapor pressure $10.1 \mathrm{~Pa}\left(10^{-4} \mathrm{~atm}\right)$ at $440 \mathrm{~K}^{(4)}$. On the other hand, the corrosion product formed on nickel in hydrogen chloride gas and gas mixtures with oxygen is $\mathrm{NiCl}_{2}$, regardless of the gas composition ${ }^{(2)}$, although iron oxides as well as $\mathrm{FeCl}_{3}$ were formed on iron in the gas mixtures ${ }^{(1)}$.

In the present work, the corrosion behavior of iron-nickel alloys in the gas mixtures is almost the same as that of iron; the corrosion rate is mainly determined by evaporation of $\mathrm{FeCl}_{3}$ melt formed by oxychlorination. Up to $673 \mathrm{~K}$ the main reaction seems to be the formation and evaporation of $\mathrm{FeCl}_{3}$ by oxychlorination. Accordingly, increasing oxygen content of gas mixtures accelerates oxychlorination and hence corrosion.

The corrosion behavior at $773 \mathrm{~K}$ was slightly different with alloy composition. The formation and evaporation of $\mathrm{FeCl}_{3}$ were active at $773 \mathrm{~K}$, and the stability of iron oxides begins to increase at this temperature. When oxygen content of the gas mixtures was not sufficiently high, corrosion suppression due to the oxide scale formation was not sufficient. Accordingly, the formation and evaporation of $\mathrm{FeCl}_{3}$ by oxychlorination were more active in the gas mixture with $50 \%$ oxygen than in the gas mixture with $20 \%$ oxygen. However, in the gas mixture with $75 \%$ oxygen the corrosion rate was lower than those in the gas mixtures with 20 or $50 \%$ oxygen due possibly to the formation of an inner iron oxide scale. Furthermore, the outer layer of the scale was $\mathrm{NiCl}_{2}$ which was relatively stable at this temperature. In the gas mixture with $75 \%$ oxygen the thicker the outer $\mathrm{NiCl}_{2}$ layer and hence the higher the nickel content of the alloy, the lower was the corrosion rate.

A massive iron oxide scale was formed as an inner layer at 873 or $973 \mathrm{~K}$. Accordingly, in the gas mixtures with higher concentrations of oxygen, such as $75 \%$, the corrosion rate was lower than that in the gas mixtures with lower concentrations of oxygen at these higher temperatures, although the corrosion rate was not significantly changed by the addition of nickel to iron.

Consequently, the addition of nickel to iron up to $20 \%$ is not effective in decreasing the corrosion rate in hot gas mixtures of hydrogen chloride and oxygen at these temperatures examined, and it seems necessary to add chromium for improvement of corrosion resistance $^{(3)}$.

\section{Summary}

The corrosion behavior of iron, $\mathrm{Fe}-12$ and $\mathrm{Fe}-20 \% \mathrm{Ni}$ alloys between 523 and $973 \mathrm{~K}$ in hydrogen chloride gas and gas mixtures of hydrogen chloride and oxygen has been studied. The results are summarized as follows:

(1) In hydrogen chloride gas, up to $673 \mathrm{~K}$ where an appreciable sublimation of chloride scale was not observed, the reaction proceeded according to nearly parabolic kinetics, and the addition of nickel to iron suppressed the corrosion rate by the formation of $\mathrm{Fe}(\mathrm{Ni}) \mathrm{Cl}_{2}$ scale. When the temperature exceeded $773 \mathrm{~K}$, there was no essential difference between the corrosion rates of pure iron and $\mathrm{Fe}-\mathrm{Ni}$ alloys, in spite of increasing scale mass due to the depression of the average sublimation rate by the addition of nickel to iron.

(2) Addition of oxygen to hydrogen chloride gas greatly accelerated corrosion of $\mathrm{Fe}-\mathrm{Ni}$ alloys even at low temperatures such as $523 \mathrm{~K}$ due to the formation and sublimation of a low melting point volatile $\mathrm{FeCl}_{3}$ by oxychlorination. The scale consisted of an outer $\mathrm{NiCl}_{2}$ layer and an inner $\alpha-\mathrm{Fe}_{2} \mathrm{O}_{3}$ layer, and in the scale-metal interface a deliquescent $\mathrm{FeCl}_{3}$-like corrosion product was formed. The scale was not uniform but contained many cracks, suggesting that oxychlorination occurred mainly in the scale-metal interface. Up to $673 \mathrm{~K}$, increasing oxygen content of the gas mixtures increased the rate of $\mathrm{FeCl}_{3}$ evaporation and hence the corrosion rate. In the gas mixture containing $20 \%$ oxygen, corrosion was accelerated with increasing temperature. When the oxygen content of the gas mixtures was raised to 50 or $75 \%$, a rise in temperature from 773 to $873 \mathrm{~K}$ decreased the corrosion rate due to thickening of the inner oxide layer. 


\section{REFERENCES}

(1) Y. Ihara, H. Ohgame, K. Sakiyama and K. Hashimoto: Corros. Sci., 21 (1981), 805.

(2) Y. Ihara, H. Ohgame, K. Sakiyama and K. Hashimoto: Corros. Sci., 22 (1982), 901.

(3) Y. Ihara, H. Ohgame, K. Sakiyama and K. Hashimoto: Corros. Sci., 22 (1982), in press.

(4) P. L. Daniel and R. A. Rapp: Advances in Corrosion Science and Technology, Ed. by R. W. Staele and M. G. Fontana, Vol. 5, Plenum Press, New
York, (1976), p. 55.

(5) O. Kubaschewski and E. LL. Evans: Metallurgical Thermochemistry, Pergamon Press London, (1958).

(6) Powder Diffraction File, File No. 1-1106, International Center for Diffraction Data, Pennsylvania, U.S.A. (1980).

(7) Powder Diffraction File, File No. 22-765, International Center for Diffraction Data, Pennsylvania, U.S.A. (1980).

(8) C. S. Tedmon, Jr.: J. Electrochem. Soc., 113 (1966), 766. 